\title{
Mitigating the Imitation of Aggressive Behaviors by Changing Children's Attitudes About Media Violence
}

\author{
L. Rowell Huesmann, Leonard D. Eron, Rosemary Klein, \\ Patrick Brice, and Paulette Fischer \\ University of Illinois at Chicago
}

\begin{abstract}
A sample of 169 first- and third-grade children, selected because of their high exposure to television violence, was randomly divided into an experimental and a control group. Over the course of 2 years, the experimental subjects were exposed to two treatments designed to reduce the likelihood of their imitating the aggressive behaviors they observed on TV. The control group received comparable neutral treatments. By the end of the second year, the experimental subjects were rated as significantly less aggressive by their peers, and the relation between violence viewing and aggressiveness was diminished in the experimental group.
\end{abstract}

Aggressive behavior in humans is known to be related to a number of physiological, psychological, familial, and cultural factors as well as the specific learning conditions to which the child is exposed (Bandura, 1977; Baron, 1977; Berkowitz, 1974a; Eron, Walder, \& Lefkowitz, 1971). However, the exact processes through which individual differences in aggression develop have been difficult to decipher. One reason for the difficulty is that manipulative experiments designed to elicit aggressive behavior toward other people are hard to justify ethically. As a result, the causes of aggressive behavior have often been inferred from observational data (field studies) rather than deduced from experimental data. Although such field studies have provided a fairly compelling link between violence viewing and aggression (Comstock, 1981; Lefkowitz \& Huesmann, 1981), they do not have the explanatory power of experiments. In the research reported in this article, we investigated children's actual ag-

This research was supported in part by grants $\mathrm{MH}$ 28280 and MH-31886 from the National Institute of Mental Health. The authors wish to acknowledge the assistance of Patricia Jones, Esther Kaplan Khain, Re- $_{7}$ becca Mermelstein, Susan Moloney, Sharon Morikawa, Vita Musonis, Erica Rosenfeld, James Stewart, Ann Washington, and Linda White in collecting the data.

Requests for reprints should be sent to $L$. Rowell Huesmann, Department of Psychology, University of Illinois at Chicago, Box 4348, Chicago, Illinois 60680. gressive behaviors toward other people with a manipulative experiment that avoided the ethical issues by being directed at reducing aggression. In particular, we attempted to mitigate the relation between aggression and television violence viewing in children through an intervention that altered the children's attitudes about aggression and violent shows.

A number of different theories have been postulated to explain the positive relation between high violence viewing and high interpersonal aggression. That such a relation exists is no longer open to serious question (Chaffee, 1972; Comstock, 1981; Huesmann, 1982; Lefkowitz \& Huesmann, 1981). However, at least five types of processes have been suggested to explain the positive relation: (a) Children imitate the specific aggressive behaviors of the actors they see on television (observational learning); (b) television violence stimulates the child, facilitating the emission of aggressive acts that may be reinforced; (c) television violence raises or lowers the emotional responsivity of the child to violence, increasing the likelihood of aggressive behavior; (d) television violence fosters accepting attitudes toward aggression, increasing the probability of aggressive behavior; and (e) television violence is watched by aggressive children because it provides opportunities to rationalize their own aggressive behavior as the norm. This list is not intended 
to be exhaustive, and the authors do not pretend to agree with or even understand how these theories predict existing data.

One interesting dimension on which these theories vary is the role of intervening cognitions in the relation between violence viewing and aggression. Although only some of the theories postulate explicit intervening cognitions (e.g., attitudes, logical rationalization), cognitions could play an intervening role in the others as well. Therefore, an intervention directed at mitigating the violenceviewing-aggression relation by altering a child's cognitions could provide useful evidence about the psychological basis of the relation.

More laboratory research has probably been directed at understanding observational learning than any other of the models. Because Bandura's first laboratory experiments (Bandura, Ross, \& Ross, 1961, 1963a, 1963b) suggested the validity of observational learning, a large number of experiments have been performed that illuminated the conditions under which specific behaviors were likely to be imitated by children in a laboratory setting (Bandura, 1965, 1977). These laboratory findings have been confirmed in the field by a number of observational studies (Belson, 1978; Eron, Huesmann, Lefkowitz, \& Walder, 1972; Lefkowitz, Eron, Walder, \& Huesmann, 1977; Singer \& Singer, 1980), suggesting that television violence is a precursor of aggressive behavior in real life. Nevertheless, it seems clear that more complex process models are needed to explain the conditions under which violence viewing and real aggressive behavior are related.

Recently, Collins (1982), Huesmann (1982), and Turner (Turner \& Layton, 1976; Turner \& Fenn, 1979) attempted to connect the effects of television violence viewing more closely to theorizing in cognitive psychology. They have suggested that aggressive problemsolving strategies may be associated with specific cues in an aggressive film and retrieved when those cues or similar cues are present. Drawing on both observational learning and Berkowitz's (1974a, 1974b) theory of media violence as an aggression-facilitating stimulus, these authors emphasize the child's cognitive processing. Under this view, three important contributors to the likelihood that a child would behave more aggressively as a result of violence viewing could be the child's perception of the violence as realistic, the child's identification with the TV character, and the child's beliefs about society's acceptance of aggression. If the child perceives the problem-solving strategy used by the actor as unrealistic and ineffective in the real world or cannot identify with the actor or believes an aggressive response is unacceptable, then the child might be less likely to encode the strategy. By "encoding" we mean the "formation of a representation of an external stimulus in the memory system" (Kintsch, 1977 , p. 485).

Alternatively, even if the child encodes, stores, and later retrieves the strategy, the child may be less likely to employ the aggressive strategy under such conditions (e.g., the action is perceived as unrealistic). In other words, in such situations the child inhibits aggressive responding.

A few experimental and field studies have found results indicating that more aggressive children do, in fact, believe television violence is more realistic (Lefkowitz et al., 1977) and that realistic films are more likely to be imitated (Feshbach, 1976). In addition, Turner and Berkowitz (1972) reported that subjects who imagined themselves as the character performing an aggressive action in a film were subsequently more likely to behave aggressively. Along these lines, Singer and Singer (1980) report that children who use prosocial imaginative play are less likely to behave aggressively than others, whereas Huesmann (1982) reports that the more a child fantasizes about aggression the more likely is a child to behave aggressively. He or she interprets such fantasy as rehearsal of aggressive behavior. As for the role of general attitudes toward aggression, it has been shown that the more television a child watches, the more accepting is the child toward aggressive behavior (Dominick \& Greenberg, 1972). Similarly, Thomas and Drabman (1975) found that exposure of children to violent scenes makes them more tolerant of aggression in others, that is, accepting it as the norm.

It follows that one might be able to reduce the effect of television violence on children by changing certain cognitions, in particular 
by teaching children that (a) television violence is an unrealistic portrayal of the real world, (b) aggressive behaviors are not as acceptable in the real world as they appear on television, and (c) one should not behave like the aggressive characters seen on TV.

Only a few previous attempts have been made to mitigate the effects of television violence. For example, Hicks (1968) and Grusec (1973) demonstrated that an adult's comments about what a child was watching could influence the likelihood that the child would imitate the observed behaviors. PitkanenPulkkinen (1979) showed that a child's general level of aggressive responding can be reduced with an appropriate cognitive intervention. A number of other interventions have been undertaken that have attempted to modify a child's reactions to other aspects of television besides violence, for example, advertising (Dorr, Graves, \& Phelps, 1980; Roberts, Christenson, Gibson, Mooser, \& Goldberg, 1980; Singer, Zuckerman, \& Singer, 1980). These studies have indicated that children's attitudes about television can be changed.

Although these results suggest that an intervention could be successful at influencing a child, it remains unclear whether, as the theories suggest, a child could be made less aggressive by changing the child's attitudes about the realism and appropriateness of the violence portrayed on television. We undertook the current study to test this theory.

\section{Experiment 1

$$
\text { Method }
$$

\section{Subjects}

The subjects were selected from a larger sample of 672 children who were participating in a 3-year longitudinal study of the effects of television on children's aggressive behavior. These 672 children represented almost the entire first- and third-grade population of Oak Park, Illinois in 1976-1977. Only those children for whom parental permission could not be obtained were excluded from the larger sample.

During 1976-1977, while enrolled in the first and third grades, these 672 subjects were asked to select the 8 television programs they preferred to watch most from each of 8 lists of 10 programs. They were then asked how often they watched each of the programs. Children were considered eligible to participate in the present experiment if they selected at least six highly violent shows and reported that they watched them most of the time (or if they selected another pattern scaled equivalently). The violence level of a program was determined by two independent raters who watched and evaluated most current programs. On a five-point violence scale they achieved an interrater reliability of .77 for 80 programs. The 98 boys and 71 girls who met this violence-viewing criterion and agreed to participate in the experiment comprised the top $27 \%$ of subjects in violence viewing among boys and the top 19\% among girls.

During the next school year, these 169 children, now in the second and fourth grades, were randomly assigned to experimental and placebo groups subject to constraints imposed by having to perform manipulations in small group sessions. Namely, each subgroup was required to consist of at least three subjects of the same sex and grade from the same school. As a result of these procedural limitations, the experimental group consisted of 92 subjects, whereas the placebo group included only 77 subjects. The composition of these groups by grade and sex is shown in Table 1.

\section{Procedure}

After pretesting on a "realistic behavior" questionnaire, the experimental subjects were exposed to three training sessions designed to reduce the effect of television violence on their behavior, whereas the control subjects were given comparable placebo treatments. The treatments were followed within a few weeks by a posttest on the realistic-behavior questionnaire. Then, 3 to 4 months later, the subjects' aggressiveness and televisionviewing behavior were reassessed as part of the larger longitudinal study.

Pretest. The experimental and control subjects were pretested in group sessions. The pretest was designed to assess how realistic each child considered the behavior of TV characters to be in three selected shows. For boys the shows were Six-Million Dollar Man, Starsky and Hutch, and Road Runner. For girls the shows were Bionic Woman, Charlie's Angels, and Road Runner. These shows were all highly popular among $6-11$ year olds ac-

Table 1

Breakdown of Subjects by Condition, Grade, and Gender

\begin{tabular}{|c|c|c|c|c|}
\hline \multirow[b]{3}{*}{ Grade } & \multicolumn{4}{|c|}{ Condition } \\
\hline & \multicolumn{2}{|c|}{ Control } & \multicolumn{2}{|c|}{ Experimenta } \\
\hline & $n$ & $\%$ & $n$ & $\%$ \\
\hline \multicolumn{5}{|c|}{ Female } \\
\hline Second & 20 & 26 & 22 & 24 \\
\hline Fourth & 12 & 16 & 17 & 18 \\
\hline \multicolumn{5}{|c|}{ Male } \\
\hline Second & 27 & 35 & 27 & 29 \\
\hline Fourth & 18 & 23 & 26 & 28 \\
\hline Total & 77 & & 92 & \\
\hline
\end{tabular}


cording to the Nielsen ratings and were classified as highly violent by our two raters. The shows ranged in "general" realism from Road Runner, for which $11 \%$ of our total sample (672) had said "tells about life just as it is," to Starsky and Hutch, for which 53\% of our sample responded that way. The realistic-behavior questionnaire contained 32 questions of three different types about the main characters in the three shows. A statement would be read to the children describing some behavior of the principal character or characters in the show, for example, "The six-million dollar man can fight three people at the same time and not get hurt." The children would then be asked three questions assessing (a) whether the child thought most people behave that way, for example, "Can most people fight . . . ?" (b) whether the child behaved that way, for example, "Can you fight ... ?" and (c) whether the child ever expected to be able to behave that way, for example, "When you grow up, will you be able to fight .... ?" Each response ("yes," "maybe," or "no") was scored on a three-point scale, and the sum of the 32 responses constituted the child's realistic-behavior score. The final questionnaire, refined through pilot testing, had an internal reliability of .78 .

Intervention. The subjects received either three training or three placebo sessions over a period of 6 to 8 weeks. Children were trained in groups of three to eight in sessions that were separated by at least 2 weeks.

The training sessions for the experimental subjects were designed to teach children three principles that, if learned, would be expected to reduce the modeling of aggressive behavior: (a) that the behaviors of the characters on these shows do not represent the behaviors of most people, (b) that camera techniques and special effects are giving the illusion that the characters are performing their highly aggressive and unrealistic feats, and (c) that the average person uses other methods to solve problems similar to those encountered by the characters. In the first experimental session, same-sex groups were shown violent TV segments to introduce them to "super hero" shows. The girls were shown segments from the Bionic Woman, and boys were shown parts of the SixMillion Dollar Man. After viewing the television segment, experimental subjects participated in a structured discussion about TV realism. First, experimental subjects heard a standardized story line in which the superhero character used violence to solve a problem. The experimenter then retold the story, this time emphasizing how ordinary people would solve the problem. Subsequently, a new plot containing a dilemma was outlined by the experimenter. Experimental subjects were then asked to think of realistic ways that the bionic woman or six-million-dollar man could solve the problem. Experimenters were prepared to ask leading questions and to provide the opportunity for every child to talk in the event that any child had difficulty in providing answers. Similar procedures were used for the second and third training sessions. For the second session, subjects of both sexes met in same-grade groups to discuss the Road Runner, which was not judged to be gender specific. Boys watched and discussed Starsky and Hutch in the third session, whereas girls met separately to examine Charlie's Angels.

For the placebo group, television programs were also shown, and the same amount of time was spent in dis- cussion as in the experimental-group sessions. However, the shows were nonviolent, and there was no instruction as to the realistic nature of television. The first session consisted of excerpts from a program on Bali folk dance, followed by a discussion of different folk dances. The second session began with a segment from the TV show Lavern and Shirley, after which subjects were encouraged to tell jokes and riddles they knew. In the third session, part of the TV show Happy Days was shown, and subjects were led in a discussion of nicknames.

Posttest. Within a few weeks after the last training or placebo session, each subject was retested on the realistic-behavior questionnaire. Then, 3 to 4 months later, a large number of measurements was taken as part of the second wave of data collection in the larger longitudinal study.

\section{Measures}

Four measures in addition to the realistic-behavior score were important for this experiment. The child's aggressiveness was measured through the peer-nomination technique both 9 months before the intervention and 3 months after. The peer-nomination technique has been widely used and is described in detail elsewhere (Eron et al., 1971; Walder, Abelson, Eron, Banta, \& Laulicht, 1961). Each child nominates as many other children as he or she wishes in response to 10 questions, such as "Who pushes and shoves other children?" Within our total longitudinal sample $(N=748)$, the internal consistency was .97 and the 1 -month stability was .91 . Television-violence-viewing, television-realism, and identification-with-television-characters scores were also recorded at both time periods. The violence-viewing scores were based on the eight programs the children said they watched most often. For each such program the child reported whether he or she watched it "once in a while," "a lot but not always," or "every time it's on." The violence score for the child was obtained by taking the mean violence score of the programs the child watched "every time" they were on. The "judgment of TV realism" score measured to what extent the child thought 10 violent programs told about life "just like it really is." The identification score measured how much the child thought he or she behaved like eight selected TV characters. Half the characters were male, half female, half aggressive, and half unaggressive. The internal consistencies of television violence viewing, judgment of TV realism, and identification with TV characters were $.75, .74$, and .60 , respectively.

\section{Results and Discussion}

The mean changes in the experimental and control subjects' realistic-behavior scores were compared to evaluate the effectiveness of the manipulation in changing the experimental subjects' beliefs. However, there was no evidence of success in this regard. Whereas the experimental group changed slightly more in the desired direction, the differences were insignificant both statistically and practically. 
In fact, neither the experimental nor the control group changed by more than $1 \%$. A discriminant analysis based on changes in the 32 individual items of the scale did locate nine items that distinguished significantly between groups, $F(9,129)=2.27, p<.025$, but the items did not conform to any interpretable category. It appears that the intervention did not affect the beliefs it was directly designed to affect. One reason may be that the mean scores were already near the "unrealistic" end of the scale before the intervention began, that is, 1.7 on a scale whose minimum was 1.0. Alternatively, the intervention simply may not have been powerful enough to alter the subjects' beliefs.

The mean scores of the subjects on aggression, violence viewing, and judgment of TV realism recorded 3 months after the intervention also showed no evidence of change. As Table 2 reveals, the intervention had no detectable effect on any of these variables. Nor did the intervention produce significant changes in the relation between aggression and TV viewing, as the regression in Table 3 reveals.

This first experimental intervention does not appear to have changed the attitudes, TVviewing behavior, or aggressiveness of the subjects after a 3-month lag. Why? First, it may be expecting too much to change real attitudes and habits on the basis of 3 hours of training. An alternative, and more interesting, explanation would be that 3 months is not a great enough lag for any changes to emerge. The form of the intervention was extremely didactic, and the children may have reacted negatively to being told what beliefs they should have about television and television characters. If this was the case, a "sleeper effect" (Gruder et al., 1978) might occur in which the intervention would eventually have an effect after the subjects' reactions to the intervention had diminished. A third and related possibility is that the experimental subjects actually encoded and retained the aggressive behaviors they observed on the violent segments they were shown as examples. Certainly; the context made these excerpts highly salient, and such a modeling effect could counteract any weak mitigating effect. In retrospect, it would seem to have been a mistake to use violent excerpts with the experimental subjects and nonviolent ones with the placebo subjects.

Finally, one must consider the possibility that the intervention, although didactic, was not directed at the appropriate variables. Consider again the information-processing model on which the intervention was based. It presumed the children encode into memory those aggressive behaviors they observe that seem useful for solving social problems. In the intervention we tried to teach the children that the behaviors they see on TV are not really happening and are not performed by most people and that other solutions to the problems exist. The hope was that the children would adopt these beliefs and either not encode the behaviors they observed on television or not employ them if recalled, that is, inhibit them. However, the evidence suggests that most children already accepted these beliefs about the unreality of the violent behaviors and still encoded, stored, retrieved, and emitted the behaviors. Therefore, a more

Table 2

Effect of the First Intervention on Mean Aggression and Television Viewing Behavior

\begin{tabular}{|c|c|c|c|c|c|c|c|c|c|c|c|c|c|}
\hline \multirow[b]{3}{*}{ Group } & \multirow[b]{3}{*}{$n$} & \multicolumn{4}{|c|}{ Peer-nominated aggression } & \multicolumn{4}{|c|}{ Television violence viewing } & \multicolumn{4}{|c|}{ Judgment of TV realism } \\
\hline & & \multicolumn{2}{|c|}{$\begin{array}{l}\text { Before } \\
\text { (1977) }\end{array}$} & \multicolumn{2}{|c|}{$\begin{array}{c}\text { After } \\
\text { (1978) }\end{array}$} & \multicolumn{2}{|c|}{$\begin{array}{l}\text { Before } \\
(1977)\end{array}$} & \multicolumn{2}{|c|}{$\begin{array}{c}\text { After } \\
(1978)\end{array}$} & \multicolumn{2}{|c|}{$\begin{array}{l}\text { Before } \\
\text { (1977) }\end{array}$} & \multicolumn{2}{|c|}{$\begin{array}{c}\text { After } \\
(1978)\end{array}$} \\
\hline & & $M$ & $S D$ & $M$ & $S D$ & $M$ & $S D$ & $M$ & $S D$ & $M$ & $S D$ & $M$ & $S I$ \\
\hline $\begin{array}{l}\text { Experimental } \\
\text { Control }\end{array}$ & $\begin{array}{r}92 \\
77\end{array}$ & $\begin{array}{l}.187 \\
.187\end{array}$ & $\begin{array}{l}.14 \\
.15\end{array}$ & $\begin{array}{l}.176 \\
.157\end{array}$ & $\begin{array}{l}.17 \\
.16\end{array}$ & $\begin{array}{l}99.9 \\
86.7\end{array}$ & $\begin{array}{l}54.2 \\
43.7\end{array}$ & $\begin{array}{l}60.8 \\
53.9\end{array}$ & $\begin{array}{l}39.3 \\
38.4\end{array}$ & $\begin{array}{l}18.3 \\
17.6\end{array}$ & $\begin{array}{l}5.2 \\
4.4\end{array}$ & $\begin{array}{l}16.2 \\
16.4\end{array}$ & $\begin{array}{l}4.2 \\
4.1\end{array}$ \\
\hline
\end{tabular}


Table 3

Correlations and Multiple Regressions Predicting 1978 Peer-Nominated Aggression for Experimental and Control Groups From Grade, Sex, and 1978 Television Viewing Behavior

\begin{tabular}{llcccc}
\hline & \multicolumn{2}{c}{ Experimental group } & & \multicolumn{2}{c}{ Placebo group } \\
\cline { 2 - 3 } \cline { 5 - 5 } \multicolumn{1}{c}{ Predictor variable } & $r$ & Beta & & $r$ & Beta \\
\hline Sex $(0=$ female, 1 = male) & $.28^{* * * *}$ & $.28^{* * * *}$ & & $.27^{* * *}$ & $.23^{* * *}$ \\
Grade (2 or 4) & .06 & .11 & & $.25^{* *}$ & .19 \\
TV violence viewing & $.19^{*}$ & .16 & & $.25^{* *}$ & .17 \\
Identification with TV characters & .16 & .21 & & .20 & $.26^{*}$ \\
Judgment of TV realism & .06 & -.01 & & -.13 & -.20 \\
& & $R^{2}=.149 ;$ & & $R^{2}=.230 ;$ \\
& & $F(5,83)=2.90, p<.025$. & & $F(5,66)=2.94, p<.005$. \\
\hline
\end{tabular}

$* p<.10{ }^{* *} p<.05 . * * * p<.01$.

direct attempt to motivate the children not to encode, store, retrieve, and employ aggressive behaviors might be needed.

\section{Experiment 2}

To investigate whether a different type of manipulation having direct characteristics would be more successful, we conducted a second intervention 9 months after the first had been completed. We used the same subjects, recognizing that we would be confounding any sleeper effect with the effect of the new manipulation. However, the design maximized the chances of detecting any real effect of the interventions.

\section{Method}

\section{Subjects}

All of the subjects from the first experiment who were still available 9 months later in early 1979 participated in the second experiment. Of the 169 subjects who completed the first experiment, 22 had moved, 2 withdrew from the longitudinal study, 3 were lost because of school administration errors, and 12 were absent from critical sessions. However, two additional control subjects who had been absent from critical sessions in 1978 were added, giving a total of 132 subjects: 72 in the experimental group and 60 in the control group. Of course, each subject remained in the same group as during the first experiment. All of the subjects were now in either the third or the fifth grade. The distribution of the subjects across groups by sex and grade was almost identical with that of the first intervention (Table 1).

In any longitudinal quasi experiment, one must consider the possibility of a group by mortality interaction as a threat to its validity. However, there is no evidence of such an effect here. In both groups $22 \%$ of the subjects were lost. Furthermore, there was no reason to expect that the first experimental intervention had a differential effect on subject mortality. Both groups in 1978 had experienced similar contact with our staff and had been exposed to procedures that appeared very similar to them.

\section{Procedure}

A more formal attitude- and behavior-change approach was adopted for the second experimental intervention. Although altering children's perceptions of television realism was still one goal of the intervention, the training also attempted to teach children directly that watching television violence was not desirable and that they should not imitate violent television programs. The design included several elements of counterattitudinal advocacy research that have been shown to produce enduring behavior changes (Cook \& Flay, 1978).

Training occurred under the pretense of producing a film to alter the attitudes of school children in Chicago. Over the course of two sessions, children in the experimental groups developed arguments about the negative aspect of television violence, wrote their arguments out, were videotaped reading their paragraphs, and viewed the videotapes of themselves and their classmates reading the paragraphs. The placebo group performed identical tasks except that the topic for their paragraphs was their hobby, and the porported purpose of the procedure was to introduce children in Chicago to new hobbies.

Pretest. All subjects were administered a short questionnaire 1 to 2 weeks before the start of the experiment. Questionnaire items were usually read to the children by their teacher during class time. Subjects were asked to respond to six attitudinal questions on a five-point scale (e.g., "How much of what kids see on television is fake?"; "How likely is it that watching a lot of violent television shows would make a kid meaner?"; "Are television shows with a lot of hitting and shooting harmless for kids?"). Each child's score was the sum of six weighted responses (three positive and three negative).

Intervention. The two training or placebo sessions were administered within a 2-week period by pairs of experimenters. Subjects met in groups of 4-10, comprised primarily of children from their own classroom. Other members of the group came from the same grade.

The experimental group's training sessions employed 
techniques that have produced behavior changes of some duration in attitude-change experiments (Cook \& Flay, 1978). These procedures included crediting the children for possession of the attitudes we wished them to adopt, inducing behaviors that would lead to the self-attribution of these attitudes, inducing perceptions of personal responsibility for an outcome related to the attitudes (e.g., Chicago schoolchildren's behaviors), inducing the perception of participation out of free choice, and promoting the perception that the consequences of their behaviors were important. In particular, the experimenters asked the children to volunteer to help in making a film to show to children in Chicago who had been "fooled by television or harmed by television violence or got into trouble because of imitating it." The experimenter introduced the self-labeling by saying that "of course you know better than to believe what you see on TV and you know that imitating what you see may be bad, but other children do not know this." As expected, all of the experimental subjects volunteered to produce the film.

Subjects spent most of the first session composing persuasive essays that they would read before a video camera when the experimenters returned in the following week. In the paragraphs they wrote, subjects were to answer three questions that had been printed on posterboard: "Tell how television is not like real life"; "Why is it bad to imitate TV violence?"; and "Why is it bad for a kid to watch too much television?" Alternative ways to write the papers were presented as examples. A child could describe a favorite show that was violent and explain what was fake about it. Another suggestion was to write about how nonviolent shows, such as Little House on the Prairie or The Brady Bunch, were more realistic or better than violent shows.

Experimenters referred to a prompting guide when children required special assistance. The guide outlined several arguments that a child might pursue in answer to each question. For example, in answer to the first question, "Tell how television is not like real life," an essay might focus on the lack of realism in shows portraying superhuman ability, the consequences of aggression in real life, the actual frequency of violence, or television's overdramatization of events. Several examples were provided for each topic. However, these were to be provided sparingly, because the main objective in writing the essay was to have the specific ideas originate with the child. If a child missed the point of a question, the experimenter emphasized the intent of the question. For example, if a child believed that imitating television violence was acceptable, the experimenter asked, "What bad things could happen to a child who carries imitating a character too far?" After essays were completed and collected, subjects were asked to keep their arguments a secret until the project was completed.

When the experimenters returned a week later, subjects were reminded of the importance of their project. For a few minutes subjects reviewed and revised their papers. The videotape of each child reading his or her paper was then made within a talk-show format. After an introduction, children read their papers and responded to short questions posed by an experimenter who served as moderator. Finally, the videotape was replayed for the subjects in the training group to view the entire group's product.

A similar procedure was followed for the placebo group, except that the essays were about "Why everyone should have a hobby." The videotapes of the children reading these essays were ostensibly to be shown to children in Chicago who did not have any hobbies. Essays written by the placebo subjects did not include any description of television viewing, guns, violence, or aggressive fantasy.

Posttest. The questionnaire that had served as a pretest was repeated 2 to 3 months later as a manipulation check. As before, the questionnaire was administered during class time, usually by the teacher. A thank-you message from the experimenters was delivered immediately before administration of the posttest as a further vehicle for impressing the subjects with the important consequences of writing and delivering their video essays. The message informed subjects "that the tapes had been a big success with the kids in Chicago who saw them."

\section{Measures}

The success of the manipulation in changing children's attitudes toward television violence was measured by the change scores on the six-item questionnaire described above. Its internal consistency was . 50 .

Four months after the intervention, data were again collected on each child as part of the longitudinal study. The same four measures used in Experiment 1 were important for this interaction: peer-nominated aggression, television violence viewing, judgment of television realism, and identification with TV characters. In addition to these variables, which were described earlier, one other question asked of all subjects was analyzed for its relation to the intervention's success. This was the extent to which the child reported reading fairy tales or being read fairy tales.

\section{Results and Discussion}

The success of this second intervention in changing the experimental subjects' attitudes about television is apparent from the scores on the attitude scale. Although the average change on the five-point scale was .20 units for the placebo group, it was 2.29 for the experimental group, $F(1,112)=12.84, p<$ .001 . This significant change over the course of 4 months reflects the movement in attitudes about TV that the experimental subjects experienced as a result of the intervention. The question, then, is whether the intervention also affected the subjects' aggressiveness and the relation between violence viewing and aggression.

The critical results are the differences in aggression revealed in Table 4. For children of the age of the present subjects, aggressiveness generally increases as age increases (Eron, Huesmann, Brice, Fischer, \& Mermelstein, 1983). As Table 4 shows, the con- 
Table 4

The Effect of the Second Intervention on

Mean Level of Aggression

\begin{tabular}{|c|c|c|c|c|c|}
\hline \multirow[b]{3}{*}{ Group } & \multirow[b]{3}{*}{$n$} & \multicolumn{4}{|c|}{ Peer-nominated aggression } \\
\hline & & \multicolumn{2}{|c|}{ Before (1978) } & \multicolumn{2}{|c|}{ After (1979) } \\
\hline & & $M$ & $S D$ & $M$ & $S D$ \\
\hline $\begin{array}{l}\text { Experimental } \\
\text { Control }\end{array}$ & $\begin{array}{l}72 \\
60\end{array}$ & $\begin{array}{l}.155 \\
.155\end{array}$ & $\begin{array}{l}.15 \\
.17\end{array}$ & $\begin{array}{l}.177 \\
.237\end{array}$ & $\begin{array}{l}.14 \\
.20\end{array}$ \\
\hline
\end{tabular}

trol group increased as expected. However, the increase for the experimental group was much less than for the control group. The difference is highly significant as evaluated by an analysis of covariance with sex, grade, and pretreatment aggression as covariates (see Table 5): Using earlier aggression as a covariate is the preferred method of analysis rather than using change score or repeated measures analysis in this situation, but these other analyses yield comparable results. The intervention appears to have reduced significantly the peer-nominated aggressive behavior of the experimental subjects over the course of the 4 months following the intervention. This difference is particularly notable because the intervention again did not significantly reduce the subject's overall level of violence viewing or the subject's judgment of the realism of television violence.

The correlations of television variables with aggression within the two groups suggest what happened in the intervention to bring about the lower aggression scores despite the fact that violence viewing on the part of subjects who were in the experimental group was

Table 5

An Analysis of Covariance of the Effect of the Second Intervention on Aggression

\begin{tabular}{lrrr}
\hline \multicolumn{1}{c}{ Source } & df & \multicolumn{1}{c}{$F$} & $p<$ \\
\hline Covariates & & & \\
$\quad$ Sex & 1 & .95 & $n s$ \\
$\quad$ Grade & 1 & .90 & $n s$ \\
$\quad$ Peer-nominated & & 63.05 & .001 \\
$\quad$ aggression & 1 & 7.29 & .008 \\
Effects group & 1 & & \\
Error & 127 & & \\
$\quad$ Total & 131 & & \\
\hline
\end{tabular}

not reduced. Table 6 shows how aggression is predicted in each group from a set of variables including sex, grade, television violence, extent of identification with TV characters, and judgment of TV realism. The most striking result in this table is the lack of a correlation between television violence and aggression in the experimental group and the continued positive relation in the placebo group, almost the same degree of relation as in the general population. The best predictor in the experimental group was identification with TV characters. Those subjects who had higher self-rated identification with TV characters had higher peer-nominated aggression scores. There was a positive but not significant relation in the placebo group between identification and aggression. The sheer amount of violence viewing by that group was sufficient to predict aggression, regardless of whether the subjects identified with the character. Gender, as would be expected, continued to be a good predictor of aggression in both groups: Boys were more aggressive than girls in all conditions. Grade level was a predictor only in the placebo group.

The multiple regressions in Table 6 show how these variables combine to predict aggression. In the placebo group the coefficients are very close to those found in the general population.' The coefficient for TV violence is positive and the largest for the TV variables. It is only marginally significant because it is significantly correlated with identification, which is also in the equation. After the intervention, however, the best prediction equation for the experimental group involves only the identification variable and not TV violence viewing. Comparing the two equations revealed that the coefficients for predicting aggression in the experimental group were significantly different from the placebo group, $F(5,103)=6.50, p<.001$. Violence viewing ceased being a significant predictor of aggression after the intervention

\footnotetext{
1 The no-treatment group consisted of a subsample of 179 subjects from the larger longitudinal study who were in the same schools and grades as the experimental and control subjects. Data on these subjects were collected in the same group sessions as the data on the experimental and control subjects, so all procedures were identical.
} 
either by itself or in conjunction with other variables.

The significance of this result must be considered in light of several other findings. Elsewhere, Huesmann, Lagerspetz, and Eron (Note 1) reported that identification with TV characters seems to catalyze the violenceviewing-aggression relation in boys in both the United States and Finland. In fact, the product of these two variables was found to be a better longitudinal predictor of a boy's aggression than either alone.

Why, then, did the intervention reduce aggression significantly and also reduce the relation between TV violence viewing and aggression but at the same time increase the relation between the child's identification with TV characters and aggression? The intervention did not change all attitudes equally. An examination of the individual items in the attitude questionnaire revealed that the change on the realism item was not significant. Experiment 1 showed that most subjects already believed television was not very realistic, so this result is not surprising. Thus, one must look to other aspects of the intervention as the cause of the changes in the experimental group. The obvious candidates are the attitudes that did change significantly, that is, beliefs about the danger of television violence ("Are television shows with a lot of hitting and shooting harmless for kids?") and about the effect of violence on aggression ("How likely is it that watching a lot of television violence would make a kid meaner?"'). The mean change in each of these attitudes was significantly greater (2.5 times greater) in the experimental than in the control group (.55 versus .22 per item on a five-point scale). However, within the experimental group, change in attitude was only weakly correlated with reduction in aggression $(r=.15, p<$ $.05)$. One reason why this correlation may be low is that amount of change on this scale of necessity depends negatively on preexisting levels of attitude. Change in attitude had a correlation of -.55 with pretest attitudes. Those who already had the desired attitude could not change more. Nevertheless, the weak correlation also suggests the possibility that change in attitude is only one dimension of the cognitive changes that reduced aggressiveness and that eliminated the relation be-

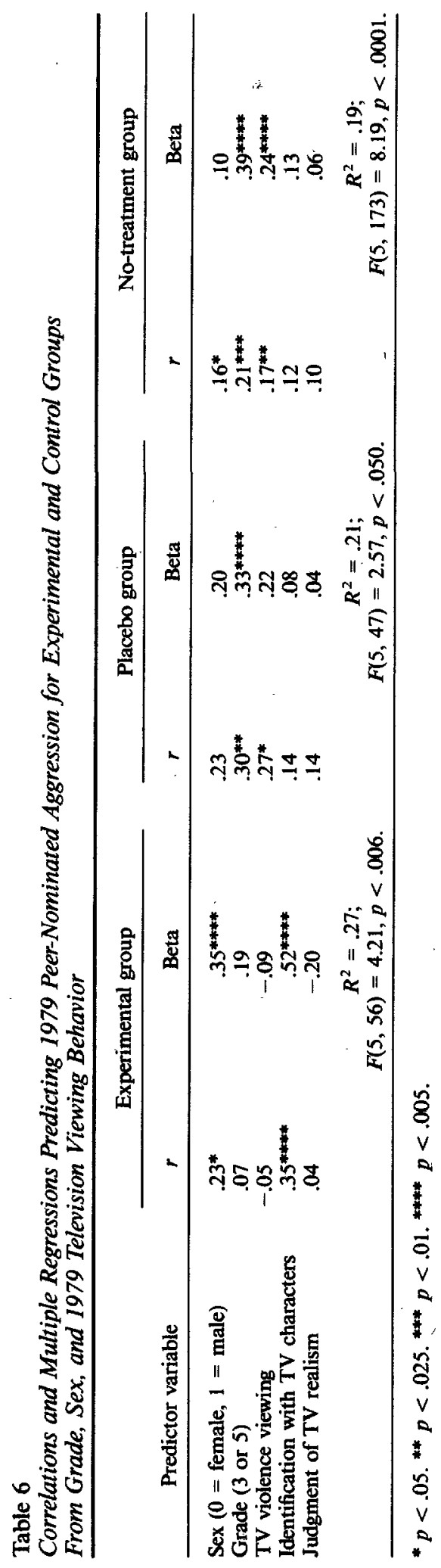


tween violence viewing and aggression within the experimental group.

One candidate for an important intervening variable suggested by the above results and the Huesmann et al. (Note 1) cross-national study is the child's identification with TV characters, that is, how much the child perceived him- or herself as being like TV characters. The regression in Table 7 reveals that the experimental subjects who changed their attitudes more were those who had identified less with TV characters 1 year earlier. The corresponding correlation was -.33 ( $p<$ $.001)$. None of the other subject variables measured 1 year earlier significantly predicted change in attitude within the experimental group. By the end of the intervention, those subjects who identified least were also the subjects who were the least aggressive within the experimental group (as Table 6 illustrated). Furthermore, the longitudinal correlation of identification with TV characters before the intervention began to aggression after the intervention terminated was $-.36(p<.01)$. Thus, those subjects who identified least with TV characters changed their attitude more and became less aggressive. As a result, identification with TV characters became the best predictor of aggression within the experimental group.

Neither the change in a subject's attitude by itself nor the change in a subject's iden-

\section{Table 7}

Correlations and Multiple Regression Predicting Attitude Change in the Experimental Group as a Function of the Child's Behaviors

\section{Year Earlier (1978)}

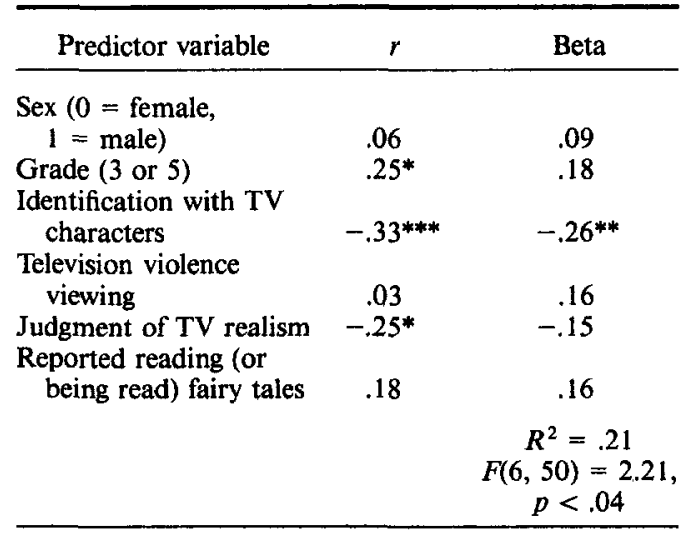

${ }^{*} p<.05 .{ }^{* *} p<.025 .{ }^{* * *} p<.01$. tification with TV characters by itself correlated significantly with change in aggression, perhaps because initial values of these variables correlate negatively with change. However, the product of change in attitude and reduction in identification did correlate significantly with reduction in aggression within the experimental group, $r(50)=-.28$, $p<.05$. In other words, after exposure to the manipulation, those subjects who came to believe that television violence could be harmful and who became less identified with TV characters were the ones who showed the greatest reduction in aggression relative to the control group.

Overall, these results were consistent with the theory that the effect of television violence on a child depends on the child's cognitions about aggressive behavior, television characters, and television violence. The manipulation altered the children's attitudes about television violence, reduced their aggressiveness, and reduced the relation between violence viewing and aggression. The final level of aggressive behavior was lowest and the attitude change was greatest for children who initially had identified less with TV characters. Also, the greatest reductions in aggression were obtained for children in the experimental group who both improved their attitudes and reduced their identification with TV characters. The precise processing connection between the subject's altered cognitions and reduction in aggression cannot be established definitively within the limits of this study. It is possible that the cognitive changes might reduce the propensity of the subject to encode or recall and emit aggressive behaviors observed on television. However, alternative explanations within other theoretical frameworks are also possible. In any case, the results allow one to conclude that within the treated group of high violence viewers, the cognitive structures of the subjects were altered so that the observation of aggressive behavior on TV was less likely to be followed by the emission of aggressive behavior and the overall level of aggression in the group was reduced.

\section{Conclusion}

Although any one of the significant changes observed after the second intervention might 
have been attributed to chance, the pattern of significant effects forms a consistent picture that is difficult to ignore. The subjects' attitudes about whether watching television violence is harmful were clearly altered in the desired direction. The change in attitudes seems to have been most pronounced for those children who did not identify strongly with TV characters. Most importantly, this change in attitudes was accompanied by a significant reduction in a child's propensity to behave aggressively. Violence viewing itself was not significantly reduced but became uncorrelated with aggression, whereas identification with TV characters became more strongly correlated with aggression.

Not only do these results suggest that mitigation of the television-violence-aggression relation is possible with reasonably simple manipulations but the results also add credence to the theory that children in one way or another are learning to be aggressive from watching violence in the media. If the violence-viewing-aggression correlation were spurious and due to some third variable, it is hard to see how the intervention could have been successful.

\section{Reference Note}

1. Huesmann, L, R., Lagerspetz, K., \& Eron, L. D. Intervening variables in the television violence-aggres sion relation: $A$ binational study. Unpublished manuscript, University of Illinois at Chicago, 1982.

\section{References}

Bandura, A, Influence of models' reinforcement contingencies on the acquisition of imitative responses. Journal of Personality and Social Psychology, 1965, 1, 589595.

Bandura, A. Social learning theory. Englewood Cliffs, N.J.: Prentice-Hall, 1977.

Bandura, A., Ross, D., \& Ross, S. A. Transmission of aggression through imitation of aggressive models. Journal of Abnormal and Social Psychology, 1961, 63, 575-582.

Bandura, A., Ross, D., \& Ross, S. A. Imitation of filmmediated aggressive models. Journal of Abnormal and Social Psychology, 1963, 66, 3-11. (a)

Bandura, A., Ross, D., \& Ross, S. A. Vicarious reinforcement and imitative learning. Journal of Abnormal and Social Psychology, 1963, 67, 601-607. (b)

Baron, R. A. Human aggression. New York: Plenum Press, 1977.

Belson, W. Television violence and the adolescent boy. Hampshire, England: Saxon House, 1978.
Berkowitz, L. External determinants of impulsive aggression. In J. DeWit \& W. Hartup (Eds.), Determinants and origins of aggressive behavior. The Hague: Mouton, 1974. (a)

Berkowitz, L. Some determinants of impulsive aggression: The role of mediated associations with reinforcements for aggression. Psychological Review; 1974, 81, 165-176. (b)

Chaffee, S. H. Television and adolescent aggressiveness (overview). In E. A. Comstock \& E. A. Rubinstein (Eds.), Television and social behavior: Vol. 3. Television and adolescent aggressiveness. Washington, D.C.: U.S. Government Printing Office, 1972.

Collins, A. Cognitive processing aspects of television viewing. In D. Pearl, L. Bouthilet, \& J. Lazar (Eds.), Television and behavior: Ten years of scientific progress and implications for the eighties (Vol. 2). Washington, D.C.: U.S. Government Printing Office, 1982.

Comstock, G. New emphases in research on the effects of television and film violence. In E. L. Palmer \& A. Dorr (Eds.), Children and the faces of television: Teaching, violence, selling. New York: Academic Press, 1981.

Cook, T. D., \& Flay, B. R. The temporal persistance of experimentally induced attitude change: An evaluative review. In L. Berkowitz (Ed.), Advances in experimental social psychology (Vol. 11). New York: Academic Press, 1978.

Dominick, J. R., \& Greenberg, B. S. Attitudes toward violence: The interaction of television exposure, family attitudes, and social class. In G. A. Comstock \& E. A. Rubinstein (Eds.), Television and social behavior: Vol. 3. Television and adolescent aggressiveness. Washington, D.C.: U.S. Government Printing Office, 1972.

Dorr, A, Graves, S. B., \& Phelps, E. Television literacy for young children. Journal of Communication, Summer 1980, 71-83.

Eron, L. D., Huesmann, L. R., Brice, P., Fischer, P., \& Mermelstein, R. Age trends in the development of aggression, sex typing, and related television habits. Developmental Psychology, 1983, 19, 71-77.

Eron, L. D., Huesmann, L. R., Lefkowitz, M. M., \& Walder, L. O. Does television violence cause aggression? American Psychologist, 1972, 27, 253-263.

Eron, L. D., Walder, L. O., \& Lefkowitz, M. M. Learning of aggression. Boston: Little, Brown, 1971.

Feshbach, $\mathbf{S}$. The role of fantasy in the response to television. Journal of Social Issues, 1976, 32(4), 71-85.

Gruder, C. L., et al. Empirical tests of the absolute sleeper effect predicted from the discounting cue hypothesis. Journal of Personality and Social Psychology, 1978, 36, 1061-1074.

Grusec, J. E. Effects of co-observer evaluations on imitation: A developmental study. Developmental Psychology, 1973, 8, 141.

Hicks, D. J. Effects of co-observer's sanctions and adult presence on imitative aggression. Child Development, 1968, 38, 303-309.

Huesmann, L. R. Television violence and aggressive behavior. In D. Pearl, L. Bouthilet, \& J. Lazar (Eds.), Television and behavior: Ten years of scientific progress and implications for the eighties (Vol. 2). Washington, D.C.: U.S. Government Printing Office, 1982. 
Kintsch, W. Memory and cognition. New York: Wiley, 1977.

Lefkowitz, M. M., Eron, L. D., Walder, L. O., \& Huesmann, L. R. Growing up to be violent: A longitudinal study of the development of aggression. New York: Pergamon Press, 1977.

Lefkowitz, M. M., \& Huesmann, L. R. Concomitants of television violence viewing in children. In E. L. Palmer \& A. Dorr (Eds.), Children and the faces of television: Teaching, violence, selling. New York: Academic Press, 1981.

Pitkanen-Pulkkinen, L. Self-control as a prerequisite for constructive behavior. In S. Feshbach \& A. Fraczek (Eds.), Aggression and behavior change. New York: Praeger, 1979.

Roberts, D. F., Christenson, P., Gibson, W. A., Mooser, L., \& Goldberg, M. E. Developing discriminating consumers. Journal of Communication, Summer 1980, 94-105.

Singer, J. L., \& Singer, D. G. Television, imagination and aggression: $A$ study of preschoolers. Hillsdale, N.J.: Erlbaum, 1980.

Singer, D. G., Zuckerman, D. M., \& Singer, J. L. Helping elementary school children learn about TV. Journal of Communication, Summer 1980, 85-93.
Thomas, M. J., \& Drabman, R. S. Toleration of real life aggression as a function of exposure to televised violence and age of subject. Merrill-Palmer Quarterly, $1975,21,227-232$.

Turner, C. W., \& Berkowitz, L. Identification with film aggressor (covert role taking) and reactions to film violence. Journal of Personality and Social Psychology, 1972, 21, 256-264.

Turner, C. W., \& Fenn, M. R. Effects of white noise and memory cues on verbal aggression. Aggressive Behavior, 1979, 5, 218-219.

Turner, C. W., \& Layton, J. F. Verbal imagery and connotation as memory-induced mediators of aggressive behavior. Journal of Personality and Social Psychology, 1976, 33, 755-7.63.

Walder, L. O., Abelson, R. P., Eron, L. D., Banta, T. J., \& Laulicht, J. H. Development of a peer-rating measure of aggression. Psychological Reports, 1961, 9, 497-556.

\section{Third Edition of the Publication Manual}

APA has just published the third edition of the Publication Manual. This new edition replaces the 1974 second edition of the Manual. The new Manual updates APA policies and procedures and incorporates changes in editorial style and practice since 1974. It amplifies and refines some parts of the second edition, reorganizes other parts, and presents new material. (See the March issue of the American Psychologist for more on the third edition.)

All manuscripts to be published in the 1984 volumes of APA's journals will be copy edited according to the third edition of the Manual. Therefore, manuscripts being prepared now should be prepared according to the third edition. Beginning in 1984 , submitted manuscripts that depart significantly from third edition style will be returned to authors for correction.

The third edition of the Publication Manual is available for $\$ 12$ for members of APA and $\$ 15$ for nonmembers. Orders of $\$ 25$ or less must be prepaid. A charge of $\$ 1.50$ per order is required for shipping and handling. To order the third edition, write to the Order Department, APA, 1400 N. Uhle Street, Arlington, VA 22201. 